\title{
Can Respiratory Therapist-Driven Protocols Improve Resource Utilization?
}

A high variability in the practice of medicine has contributed, in part, to higher healthcare costs and poor adherence to evidence-based interventions. For this reason, protocol-based strategies have been developed to reduce the lack of concordance in an attempt to improve clinical outcomes. In the respiratory care setting, non-physiciandriven protocols have been compared with physician-directed orders in single and multiple/simultaneous interventions (oxygen titration, bronchopulmonary hygiene, bronchodilator, and hyperinflation therapy). ${ }^{1-6}$ These studies have shown an improvement in cost and allocation of non-ICU patients when respiratory-therapy-protocol-based care was used. ${ }^{1-6}$ Nevertheless, the effects of bronchodilator therapy as a single intervention using a respiratorytherapy protocol are less known.

See the Original Study on Page 431

Bronchodilator therapy, a common practice in hospital and emergency departments, is the cornerstone in the management of airway flow obstruction. The institution of specialized protocols by qualified respiratory therapists (RTs), may potentiate the conversion to more cost-effective therapies by physicians and provide valuable education for patients. ${ }^{7}$ The goal of these protocols is to deliver effective and appropriate care to patients who would benefit from these treatments. ${ }^{5,6}$ Moreover, when evidence is present for certain therapies, protocols help to eliminate the variability in delivery of care and may contribute to decreased healthcare cost.

In this issue of Respiratory CARE, Kallam and colleagues report an analysis of prospectively collected data on 48 patients from the initial phase of a quality improvement project. ${ }^{8}$ This quality improvement project consisted of the transition of delivering respiratory care services from physician-ordered bronchodilator therapy to an RT-driven bronchodilator protocol strategy. ${ }^{8}$ During a 2 weeks period, RTs administered physician-ordered bronchodilator therapy with an assessment of patients' clinical status while simultaneously recording recommendations using an RTdriven bronchodilator protocol. Clinical data were collected on a daily basis as long as RT services were requested. Based on an evaluation tool that included clinical findings, patients were categorized according to their level of se- verity, from high severity and/or instability (level 1) to low severity and/or clinical stability (level 5). After the assignment of severity, the frequency of aerosol therapy was determined based on a predefined chart.

The main findings of this study were that the use of an RT-driven bronchodilator protocol reduced hypothetically the frequency of bronchodilator therapy, when compared to physician-ordered strategy. In addition, there was poor concordance of bronchodilator therapy frequency between physician-ordered treatment and RT protocols. Finally, a potentially reduced cost was observed when RT-driven protocols were used.

The present study is in line with previous observations from 2 randomized controlled trials, where a lower cost was found after applying respiratory care protocols. ${ }^{5,6}$ Stoller et al randomized 145 adult non-ICU patients to receive either RT-protocol or physician-directed respiratory care orders. ${ }^{5}$ There was no difference in baseline demographics, but a higher concordance of RT-protocol with the standard of care plan was observed over the physiciandirected care $(82 \pm 16 \%$ vs $64 \pm 21 \%)(P<.001)$. The true cost of respiratory care was slightly lower in the RTprotocol group. Similarly to this study, Kollef et al evaluated 694 patients who received respiratory care either by an RT-driven protocol or by orders from managing physicians. ${ }^{6}$ In the RT protocol group, fewer respiratory therapy treatments and lower discordance with standard of care were observed. Moreover, lower respiratory care cost and higher administration of metered-dose inhaler bronchodilator therapy were associated with the use of protocols. ${ }^{6}$

Can reduced costs translate into improved outcomes? Several studies have shown that RT-driven protocols can not only optimize healthcare resource allocation but also have other important benefits. RT-driven protocols have shown to reduce medication side effects, hospital stay, prevent admissions to the ICU, and increase treatment adherence while reducing overall costs. ${ }^{5,6,9,10}$ The reasons behind the benefit of these strategies is complex, but may be partially explained by an increase in the frequency and duration of patient evaluation by the provider and a structured approach to the administration of therapy. A proportionally lower number of clinical encounters by the physicians, compared to the RTs, may justify the poor 


\section{Can Respiratory Therapist-Driven Protocols Improve Resource Utilization?}

concordance between physician-driven protocols and RTdriven protocols.

As with the use of supplemental oxygen and bronchial hygiene therapies, bronchodilator therapy guided by respiratory care protocols improves the allocation of respiratory care services. These protocols can be conducted by either single treatments or by a more comprehensive plan derived from specific therapies according to the patient's needs. The study of Kallam and colleagues highlights how an RT-driven protocol could have substantial impact on healthcare costs. ${ }^{8}$ Future ongoing studies will confirm if the reduction of costs may also have an important impact on clinical outcomes.

Diego Jose Maselli MD Juan Felipe Fernandez MD Division of Pulmonary Diseases and Critical Care University of Texas Health Science Center at San Antonio San Antonio, Texas

The authors have disclosed no conflicts of interest.

Correspondence: Diego Jose Maselli MD, Division of Pulmonary Diseases and Critical Care, University of Texas Health Science Center at San Antonio, 7400 Merton Minter, MC 111E, San Antonio TX 78229. Email: masellicacer@uthscsa.edu.

DOI: $10.4187 /$ respcare. 02353

\section{REFERENCES}

1. Nielsen-Tietsort J, Poole B, Creagh CE, Repsher LE. Respiratory care protocol: an approach to in-hospital respiratory therapy. Respir Care 1981;26(5):430-436.

2. Zibrak JD, Rossetti P, Wood E. Effect of reductions in respiratory therapy on patient outcome. N Engl J Med 1986;315(5):292-295.

3. Hart SK, Dubbs W, Gil A, Myers-Judy M. The effects of therapist evaluation of orders and interaction with physicians on the appropriateness of respiratory care. Respir Care 1989;34(3):185-190.

4. Shrake KL, Scaggs JE, England KR, Henkle JQ, Eagleton LE. Benefits associated with a respiratory care assessment-treatment program: results of a pilot study. Respir Care 1994;39(7):715-724.

5. Stoller JK, Mascha EJ, Kester L, Haney D. Randomized controlled trial of physician-directed versus respiratory therapy consult service directed respiratory care to adult non-ICU inpatients. Am J Respir Care Med 1998;158(4):1068-1075.

6. Kollef MH, Shapiro SD, Clinkscale D, Cracchiolo L, Clayton D, Wilner R, Hossin L. The effect of respiratory therapist-initiated treatment protocols on patient outcomes and resource utilization. Chest 2000;117(2):467-475.

7. Tenholder MF, Bryson MJ, Whitlock WL. A model for conversion from small volume nebulizer to metered dose inhaler aerosol therapy. Chest 1992;101(3):634-637.

8. Kallam A, Meyerink K, Modrykamien AM. Physician-ordered aerosol therapy versus respiratory therapist-driven aerosol protocol: the effect on resource utilization. Respir Care 2013;58(3):431-437.

9. Colice GL, Carnathan B, Sung J, Paramore LC. A respiratory therapist-directed protocol for managing inpatients with asthma and COPD incorporating a long-acting bronchodilator. J Asthma 2005; 42(1):29-34.

10. Harbrecht BG, Delgado E, Tuttle RP, Cohen-Melamed MH, Saul MI, Valenta CA. Improved outcomes with routine respiratory therapist evaluation of non-intensive- care-unit surgery patients. Respir Care 2009;54(7):861-867. 